\title{
Heat Transfer Characteristics of Superheated Steam Combined with Far Infrared Heating
}

\author{
Tomone Amatsubo, Yoshio Hagura and Kanichi Suzuki* \\ Graduate School of Biosphere Science, Hiroshima University, 1-4-4 Kagamiyama, Higashihiroshima, 739-8528, Japan
}

Received April 6, 2005; Accepted November 7, 2005

\begin{abstract}
The heat transfer characteristics of superheated steam (SHS) combined with far infrared heating (FIH) by a ceramic heater were compared with those of SHS and FIH performed separately. The heat transfer rate was evaluated from the drying rate of the water for each heating mode under the prescribed conditions. The heat transfer rate in SHS alone could be estimated well from semi-theoretical equations, which use an established empirical equation for the convective heat transfer coefficient. But the estimated values of the heat transfer rate in FIH were slightly smaller than the observed values. This indicates that the natural convective heat transfer rate should be slightly larger than that calculated using the empirical equation. FIH greatly enhanced the heat transfer rate of SHS. Further, some SHS stagnated in the vicinity of the ceramic heater and consequently was heated to a higher temperature, enabling additional radiative heat transfer. The eff ect of FIH on the heat transfer rate increased as the temperature difference between the ceramic heater and the SHS increased.
\end{abstract}

Keywords: superheated steam, far infrared heating, heat transfer rate, energy efficiency

\section{Introduction}

Today, the food industry is putting great effort into developing innovative processes to produce high-quality, safe food products, as a response to strong consumer demand for healthy food. Recently, the application of superheated steam (SHS) to thermal food processing has been receiving increasing attention. One of the reasons for this is that SHS treatment is expected to heat or dry foodstuffs without oxidation.

SHS is gaseous water generated by heating evaporated water, i.e. steam, to a higher temperature than the boiling point of water, $\mathrm{T}_{\mathrm{b}}$. SHS is perfectly transparent and behaves both as a dry hot gas and as steam. Wet materials can be dried or roasted in SHS, just like in hot air. On the other hand, SHS condenses to water easily when it comes into contact with a material whose temperature is lower than $\mathrm{T}_{\mathrm{b}}$, and wets the material. The change in weight of the material due to the simultaneous wetting and drying in SHS depends on the temperature and flow rate of the SHS (Nishimura, et al., 1989). Materials can be heated without oxidation in SHS, because there is almost no $\mathrm{O}_{2}$ in SHS. These characteristics are unique to SHS treatment, distinguishing it from other thermal treatments which use hot air consisting mainly of $\mathrm{N}_{2}, \mathrm{O}_{2}$, and $\mathrm{H}_{2}$. SHS also has a high emissivity which allows radiative heating to occur, because the heat transfer in SHS is carried out by both convective and radiative heating, in contrast to hot air or hot $\mathrm{N}_{2}$ gas, which only allows convective heat transfer. Chow and Chung (1983), Yoshida and Hyodo (1970) and Wu, et al., (1989) have investigated

* To whom correspondence should be addressed.

E-mail: suzukan@hiroshima-u.ac.jp the heat transfer rates in SHS and hot air, and concluded that the heat transfer rate in SHS is higher than that in hot air at temperatures higher than the reverse-point temperature. Shibata, et al., (1988) have investigated the mechanism of drying in SHS, and reported that the critical moisture content for SHS drying was lower than that for hot-air drying, and that the drying rate in SHS during the falling-rate period was higher than that in hot air. Because of these interesting properties of SHS, many attempts have been made to apply SHS to thermal food processing, such as drying, roasting, sterilization, etc. Taechapairoj, et al., (2003) and Li, et al., (1993) have investigated the optimum heat transfer rate for drying unhusked rice and tortilla chips and have examined the properties of the end products. Iyota, et al., (2001) have investigated the optimum SHS treatment conditions for potatoes. Further, Nishioka, et al., (2004) have reported that SHS is useful for producing high-quality boiled-dried adductor muscles of scallop (shiraboshi). Fraile and Burg (1997) have studied the reheating of chilled ready-cooked dishes in SHS, and reported differences in the sensory attributes of the products, particularly in the surface color.

Although SHS has many interesting characteristics which can be applied to food processing, it has one serious drawback. A larger amount of energy is necessary to generate SHS than hot air of the same temperature. This is due to the fact that, to generate SHS, latent heat is needed to make steam from water, in addition to the heat needed for warming the water to $\mathrm{T}_{\mathrm{b}}$ and then warming the steam from $\mathrm{T}_{\mathrm{b}}$ to the desired SHS temperature. In contrast, only sensible heat is needed to generate hot air. Consequently, the SHS process is less energy-efficient and 


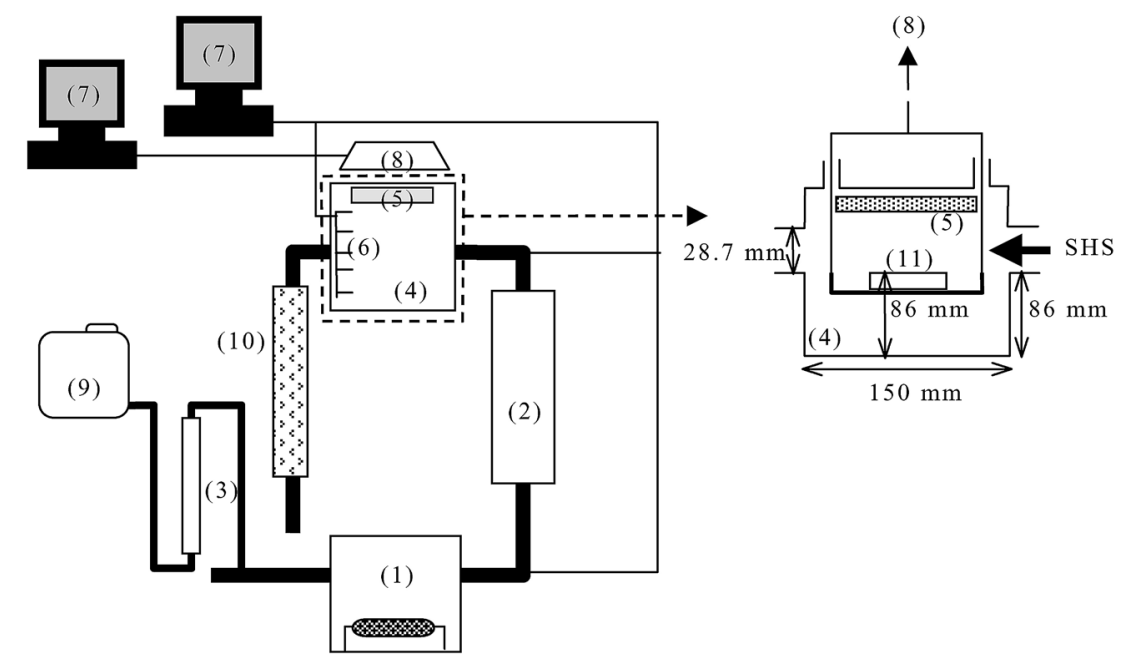

Fig. 1. Schematic diagram of the experimental apparatus. (1) Boiler, (2) Super heater, (3) Flow meter of water, (4) Test chamber, (5) Ceramic heater, (6) Thermocouples, (7) Personal computer, (8) Balance, (9) Water tank, (10) Condenser, (11) Stainless steel pan.

has a higher running cost compared to the hot-air process. Therefore, it is very important to improve the thermal efficiency of SHS treatment.

The characteristics of SHS treatment can be summarized as follows: 1) rapid heating at the initial heating stage due to the condensation of water, 2) heating without oxidation, and 3) a high heating rate due to radiative heating in addition to convective heating. Thus, the authors intended to develop a novel SHS process with improved energy efficiency, without losing the main advantages of SHS treatment. The solution was to combine SHS with far infrared heating (FIH). FIH has been widely used for thermal food treatment, such as baking and roasting. FIH should be used with only a minimum amount of SHS, to guarantee 1) rapid heating and 2) thermal treatment without oxygen. Most of the heat transfer is assured by the radiative heating of FIH. Therefore, the new process is expected to greatly reduce the energy consumption, because it does not need a huge amount of SHS, in contrast to the conventional SHS process.

The objective of this study was to investigate the heat transfer characteristics of the new heating process in which SHS is combined with FIH. For this purpose, the heat transfer rates of SHS +FIH were compared with the heat transfer rates of SHS and FIH separately. The heat transfer rate under each heating condition was estimated semi-empirically by taking into account the temperature and flow rate of SHS and the surface temperature and area of the FIH heater.

\section{Materials and Methods}

Experimental apparatus Figure 1 shows a schematic diagram of the experimental apparatus. Saturated steam is evaporated from a boiler (1) with an electric heater at atmospheric pressure. Then, it is heated in an electric superheater (2) to the desired temperature. The volumetric flow rate of the superheated steam (SHS) is regulated by adjusting the electric input to the boiler, and checked by a flow meter for the water (3). The temperature of the SHS is controlled by the electric input to the superheater. The cube-shaped test chamber (4) is $150 \mathrm{~mm} \times 150 \mathrm{~mm} \times$ $150 \mathrm{~mm}$. A ceramic heater (Nihon Heater Corporation, Tokyo, Japan, HTE-500) for far infrared heating (5) is installed on the upper wall of the test chamber. The outside of the wall of the test chamber is surrounded with a ribbon heater so that the wall temperature is kept constant $\left(< \pm 3.5^{\circ} \mathrm{C}\right)$ at the same temperature as the SHS. All parts of the apparatus from the boiler to the test chamber are sufficiently insulated with an insulator. Thermocouples (K-type) (6) are inserted into the test chamber to measure the temperatures of the upper wall, lower wall, surface of the ceramic heater and superheated steam, as well as the sample. These temperatures are recorded on a personal computer (7) through a data logger (Date Logger AD 7400, A \& D Corporation, Tokyo, Japan). The sample water in the stainless-steel pan $(\mathrm{D}=51 \mathrm{~mm}, \mathrm{H}$ $=13 \mathrm{~mm}$ ) is placed on a tray suspended by a fine wire connected to a balance (8).

Experimental method Hot distilled water was poured into the sample pan, and placed on the tray in the test chamber. The change in weight of the sample due to drying was automatically measured by the balance connected to the computer. The heat transfer rate for each heating condition was evaluated based on the constant drying rate. The average values obtained from three measurement runs for each condition were used for analysis. The experimental conditions were as follows:

Flow rate of superheated steam: $10 \mathrm{~g} / \mathrm{min} \sim 30 \mathrm{~g} / \mathrm{min}$

Superheated steam temperature: $130^{\circ} \mathrm{C} \sim 180^{\circ} \mathrm{C}$

Ceramic heater temperature: $150^{\circ} \mathrm{C} \sim 500^{\circ} \mathrm{C}$

The flow velocity of the SHS on the sample surface was assumed to be the same value as the mean inlet velocity, because the distance between the inlet of the SHS and the center of the sample was less than three times the length of the inlet diameter. The velocity values $(0.52 \mathrm{~m} / \mathrm{s} \sim 1.75$ $\mathrm{m} / \mathrm{s}$ ) were evaluated by taking into account the tempera- 
ture dependence of the density of SHS.

\section{Results and Discussion}

Heat transfer in superheated steam The mechanism of heat transfer in SHS was assumed to be as follows. The total heat transfer rate to the sample per unit area, $\mathrm{q}_{\mathrm{s}}$ $\left[\mathrm{W} / \mathrm{m}^{2}\right]$, can be expressed as the sum of the forced convective heat transfer rate, $\mathrm{q}_{\mathrm{sc}}$, the radiative heat transfer rate, $\mathrm{q}_{\mathrm{sr}}$, from the SHS and the radiative heat transfer rate from the wall of the test chamber, $\mathrm{q}_{\mathrm{w}}$ :

$$
\begin{aligned}
q_{\mathrm{s}} & =q_{\mathrm{sc}}+q_{\mathrm{sr}}+q_{\mathrm{w}} \\
& =\left(h_{\mathrm{sc}}+h_{\mathrm{r}}\right)\left(T_{\mathrm{s}}-T_{\mathrm{b}}\right)+\boldsymbol{\sigma}\left(T_{\mathrm{w}}{ }^{4}-T_{\mathrm{b}}{ }^{4}\right) F \quad \ldots . \cdot \text { Eq. }(1),
\end{aligned}
$$

where $T[\mathrm{~K}]$ is the temperature, $\sigma$ is the Stefan-Boltzmann constant $\left(5.675 \times 10^{-8}\left[\mathrm{~W} /\left(\mathrm{m}^{2} \cdot \mathrm{K}^{4}\right)\right]\right)$ and $F[-]$ is a combined factor related to the emissivity and the angle factor of radiative heat transfer. The subscripts $\mathrm{b}, \mathrm{s}$ and $\mathrm{w}$ indicate the boiling point of water, superheated steam and wall, respectively. It is commonly considered that the heat transfer rate to the water in the sample pan is the sum of the rates to the water surface and side and bottom walls of the pan. But in order to avoid such a complicated analytical treatment of the heat transfer, we simplified the analysis by making the approximation that the heat transfer rate to the water is mainly due to the convective heat transfer rate to the water surface. The film heat transfer coefficient for forced convection, $h_{\mathrm{sc}}\left[\mathrm{W} /\left(\mathrm{m}^{2} \cdot \mathrm{K}\right)\right]$, was calculated using the following empirical equation for a plate in the laminar flow region (Rohsenow and Choi, 1961):

$h_{\mathrm{sc}}=0.664(k / L) \operatorname{Re}^{1 / 2} \operatorname{Pr}^{1 / 3} \quad$ for $0.6<\operatorname{Pr}<15 \quad \cdots \cdots$ Eq. (2),

where $R e=L u_{\mathrm{av}} \rho / \mu[-]$ is the Reynolds number, in which $L[\mathrm{~m}]$ is the diameter of the sample, $u_{\mathrm{av}}[\mathrm{m} / \mathrm{s}]$ is the mean velocity of the SHS on the sample, and $\rho\left[\mathrm{kg} / \mathrm{m}^{3}\right]$ and $\mu$ $[\mathrm{Pa} \cdot \mathrm{s}]$ are the density and the viscosity of the SHS, respectively. $\operatorname{Pr}[-]$ is the Prandtl number of the SHS and $k[\mathrm{~W} /(\mathrm{m} \cdot \mathrm{K})]$ is the thermal conductivity. In this study, the value of $\mathrm{L}$ was taken to be the side length $(=45$ $\mathrm{mm}$ ) of the square, which had an equivalent area of a circular plate. The radiative heat transfer coefficient, $\mathrm{h}_{\mathrm{r}}$ $\left[\mathrm{W} /\left(\mathrm{m}^{2} \cdot \mathrm{K}\right)\right]$, was estimated from the following equation (Rohsenow and Choi, 1961):

$$
\begin{array}{r}
h_{\mathrm{r}}=\boldsymbol{\sigma}\left(T_{\mathrm{s}}^{2}+T_{\mathrm{b}}^{2}\right)\left(T_{\mathrm{s}}+T_{\mathrm{b}}\right) /\left[\left(1 / \varepsilon_{1}\right)-\left(A_{1} / A_{2}\right)\left\{1-\left(1 / \varepsilon_{2}\right)\right\}\right] \\
\cdots \cdots \text { Eq. }(3),
\end{array}
$$

where $\varepsilon_{1}[-]$ is the emissivity of water, $\varepsilon_{2}[-]$ is the emissivity of superheated steam, and $A_{1}$ and $A_{2}\left[\mathrm{~m}^{2}\right]$ are the surface area of the sample and the area of the gas region surrounding the sample, respectively. In this study, 0.95 (water at $100^{\circ} \mathrm{C}$ ) and 0.22 (superheated steam at $200^{\circ} \mathrm{C}$ ) were substituted for $\varepsilon_{1}$ and $\varepsilon_{2}$, respectively (Tanishita, 1986). The value of $F$ in Equation (1) was assumed to be 0.9 , taking into account the geometry and the materials of the test chamber. The usefulness of this $F$ value was confirmed experimentally by changing the temperature of the wall. The influence of the heat transfer from the side and bottom wall of the sample pan was assumed to be negligible compared with the total heat transfer rate.

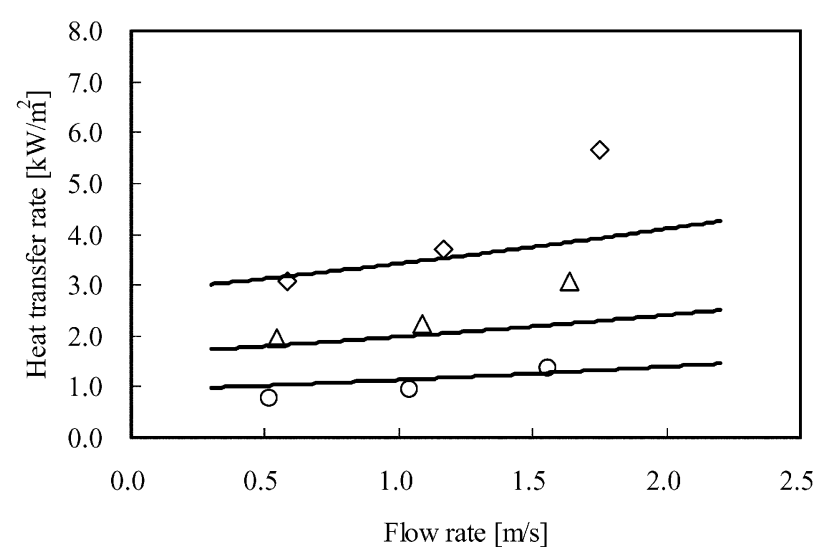

Fig. 2. The effect of the flow rate of superheated steam on the heat transfer rate.

$\bigcirc$ SHS $130^{\circ} \mathrm{C} ; \triangle$ SHS $150^{\circ} \mathrm{C} ; \diamond$ SHS $180^{\circ} \mathrm{C}$.

Solid lines: calculated values from Equations $(1) \sim(3)$.

The heat transfer rates evaluated from the constant drying rates in superheated steam (SHS) at three temperatures are shown in Figure 2. Each plot indicates the measured value, and the solid lines are the values calculated using Equations (1) (3) under the described conditions. The heat transfer rate increased as the flow rate of the SHS increased at each temperature, due to the increase in the convective heat transfer coefficient. The heat transfer rate depended also on the temperature of the SHS. The calculated values agreed with the experimental values when the numeric values were substituted into Equation (2). However, some differences were found when the flow velocity of the SHS became high. One of the reasons for this is considered to be the fact that the influence of the convective heat transfer from the SHS to the side and bottom walls of the sample pan might not be negligible when the flow rate of the SHS is higher than 20 $\mathrm{g} / \mathrm{min}$. These results show that the heat transfer rate of SHS can be estimated by Equations (1) (3) when the flow rate of the SHS is less than $20 \mathrm{~g} / \mathrm{min}$ under the experimental conditions used in this study. But, the simplified analysis for the convective heat transfer expressed in Equation (2) should be reexamined.

Heat transfer in far infrared heating in air In this heating mode, the total heat transferred to the sample was assumed to be the sum of the heat due to radiation from the ceramic heater, natural air convection and radiation from the wall of the test chamber. Thus, the heat transfer rate of $\mathrm{FIH}, \mathrm{q}_{\mathrm{i}}$, can be expressed as follows:

$$
\begin{aligned}
q_{\mathrm{i}} & =q_{\mathrm{h}}+q_{\mathrm{c}}+q_{\mathrm{w}} \\
& =\boldsymbol{\sigma}\left(T_{\mathrm{h}}{ }^{4}-T_{\mathrm{b}}{ }^{4}\right) F_{\mathrm{h}}+h_{\mathrm{c}}\left(T_{\mathrm{a}}-T_{\mathrm{b}}\right)+\boldsymbol{\sigma}\left(T_{\mathrm{w}}{ }^{4}-T_{\mathrm{b}}{ }^{4}\right) F_{\mathrm{w}} \\
\cdots \cdots \text { Eq. } & (4),
\end{aligned}
$$

where $q_{\mathrm{h}}$ and $q_{\mathrm{w}}$ are the radiative heat transfer rates from the heater and wall, respectively, and $\mathrm{q}_{\mathrm{c}}$ is the natural convective heat transfer rate. The subscripts $a$ and $h$ stand for air and heater, respectively. The air temperature, $T_{\mathrm{a}}$, was measured at nearly the middle position between the sample surface and the ceramic heater. The temperature of the sample surface, $T_{\mathrm{b}}$, in this heating 


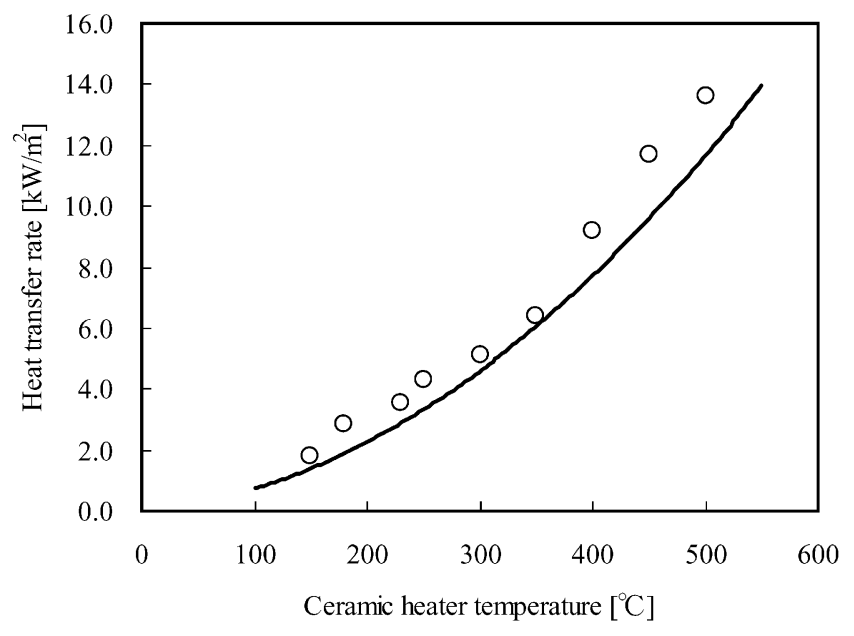

Fig. 3. Heat transfer rate for far infrared heating in air. Omeasured values.

Solid line: calculated values from Equations (4) and (5).

mode was determined by using a psychrometric chart for the high temperature region (The Society of Chemical Engineers, 1988). The factors $F_{\mathrm{h}}$ and $F_{\mathrm{w}}$ were determined to be $0.25 F$ and $0.75 F$, respectively, from the ratio of the area of the ceramic heater to that of the wall. The heat transfer coefficient for natural convection, $h_{\mathrm{c}}\left[\mathrm{W} /\left(\mathrm{m}^{2}\right.\right.$. $\mathrm{K})$, was calculated from the following equation (McAdams, 1933):

$$
\begin{array}{r}
h_{\mathrm{c}}=0.54(k / L)(G r \cdot P r)^{1 / 4} \text { for } 10^{5}<G r \cdot \operatorname{Pr}<2 \cdot 10^{7} \\
\cdots \cdots \cdot \text { Eq. }(5),
\end{array}
$$

where $G r=g L^{3} \rho^{2} \beta \Delta T / \mu^{2}[-]$ is the Grashof number, in which $\mathrm{g}$ is the gravitational constant, $\beta\left(=3.67 \times 10^{-3}[1 /\right.$ $\mathrm{k}]$ ) is the expansion coefficient of air (Perry, 1963) and $\Delta T$ $[\mathrm{K}]$ is the difference between the air temperature and the surface temperature of the sample.

The heat transfer rates of FIH obtained from the drying rates are plotted in Figure 3. The values calculated using Equations (4) and (5) are shown by solid lines. As can be seen, the heat transfer rate increased as the surface temperature of the ceramic heater increased, because of the increase in both the radiative and natural convective heat transfer. The equations account for the general trend of heat transfer in FIH, even though the calculated values were slightly smaller than the observed values. The reason for this might be due to the small estimation of the natural convection by Equation (5) or the radiative factor $F$.

Heat transfer in superheated steam combined with far infrared heating The heat transfer rate of SHS combined with FIH is more complicated than that of SHS alone or FIH alone. We assumed that the total heat transferred to the sample is the sum of the heat transferred by forced convection and radiation from the SHS and the radiation from the wall and the ceramic heater. Thus, the total heat transfer rate, $\mathrm{q}_{\mathrm{si}}$, can be expressed as follows:

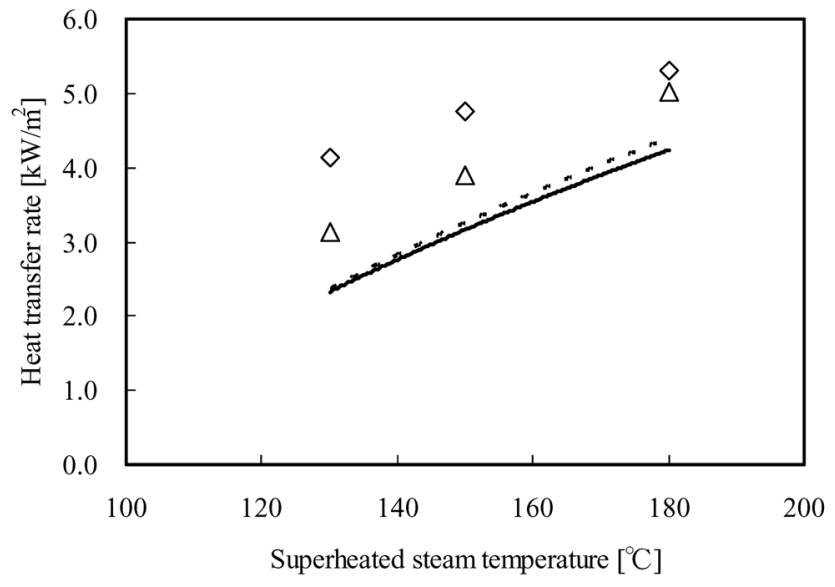

Fig. 4. Comparison of the measured heat transfer rates with the calculated values from the Equation (6).

Ceramic heater temperature: $250^{\circ} \mathrm{C}$.

Flow rate: $\triangle 0.5 \mathrm{~m} / \mathrm{s} ; \diamond 1.0 \mathrm{~m} / \mathrm{s}$.

The solid and broken lines show calculated values for flow rates of $0.5 \mathrm{~m} / \mathrm{s}$ and $1.0 \mathrm{~m} / \mathrm{s}$, respectively.

$$
\begin{aligned}
q_{\mathrm{i}} & =q_{\mathrm{sc}}+q_{\mathrm{sr}}+q_{\mathrm{h}}+q_{\mathrm{w}} \\
& =\left(h_{\mathrm{sc}}+h_{\mathrm{r}}\right)\left(T_{\mathrm{s}}-T_{\mathrm{b}}\right) \\
& +\boldsymbol{\sigma}\left(T_{\mathrm{h}}{ }^{4}-T_{\mathrm{b}}{ }^{4}\right) F_{\mathrm{h}}+\boldsymbol{\sigma}\left(T_{\mathrm{w}}{ }^{4}-T_{\mathrm{b}}{ }^{4}\right) F_{\mathrm{w}}
\end{aligned}
$$

The heat transfer rates calculated with Equation (6) were compared with the experimental values, as shown in Figure 4. The observed values were considerably larger than the calculated values (solid lines). Therefore, an additional heat source had to be considered to account for the difference. We hypothesized that the SHS stagnated just under the ceramic heater, and that the SHS around the heater was heated by the heater to a temperature higher than the inlet temperature. Thus, Equation (6) was corrected as follows:

$$
\begin{aligned}
q_{\mathrm{i}} & =q_{\mathrm{sc}}+q_{\mathrm{sr}}+q_{\mathrm{h}}+q_{\mathrm{w}} \\
& =\mathrm{h}_{\mathrm{sc}}\left(T_{\mathrm{s}}-T_{\mathrm{b}}\right)+h_{\mathrm{r}}\left(T_{\mathrm{su}}-T_{\mathrm{b}}\right) \\
& +\boldsymbol{\sigma}\left(T_{\mathrm{h}}{ }^{4}-T_{\mathrm{b}}{ }^{4}\right) \mathrm{F}_{\mathrm{h}}+\boldsymbol{\sigma}\left(T_{\mathrm{w}}{ }^{4}-T_{\mathrm{b}}{ }^{4}\right) \mathrm{F}_{\mathrm{w}}
\end{aligned}
$$

where $T_{\mathrm{su}}\left(T_{\mathrm{s}}<T_{\mathrm{su}}<T_{\mathrm{h}}\right)$ is the effective temperature of the SHS, which gives the radiative heat transfer rate of all of SHS, including the SHS stagnating around the heater. The values of $h_{s c}$ and $h_{r}$ were calculated using Equations (2) and (3), respectively.

The heat transfer rates calculated using Equation (7) were compared with the observed values shown in Figure 5. When the proper temperature was chosen for $\mathrm{T}_{\mathrm{su}}$, the calculated values agreed fairly well with the experimental values, as shown in Figure 5. The effective temperature of the SHS was slightly lower than the surface temperature of the ceramic heater, as shown in Table 1. From this result it is expected that the combination of SHS with FIH possibly resulted in an unexpected benefit, namely the enhancement of the heat transfer rate due to the additional radiative heating from the stagnating SHS which was heated to a higher temperature by the ceramic heater.

Relationship between the surface temperature of the 


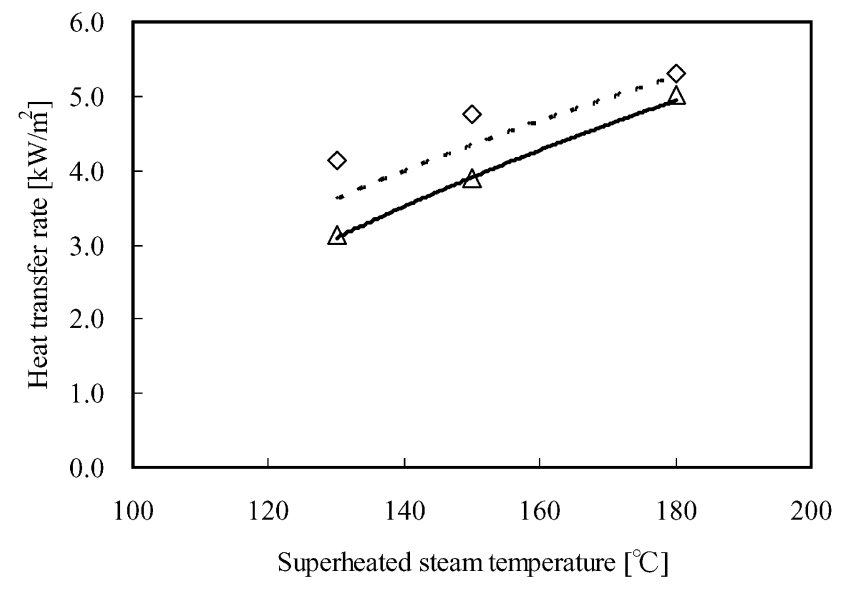

Fig. 5. Comparison of the measured heat transfer rates with the calculated values from the Equation (7) using effective temperatures of the SHS stagnated under the heater.

Ceramic heater temperature: $250^{\circ} \mathrm{C}$.

Flow rate: $\triangle 0.5 \mathrm{~m} / \mathrm{s} ; \diamond 1.0 \mathrm{~m} / \mathrm{s}$.

The solid and broken lines show calculated values for flow rates of $0.5 \mathrm{~m} / \mathrm{s}$ and $1.0 \mathrm{~m} / \mathrm{s}$, respectively.

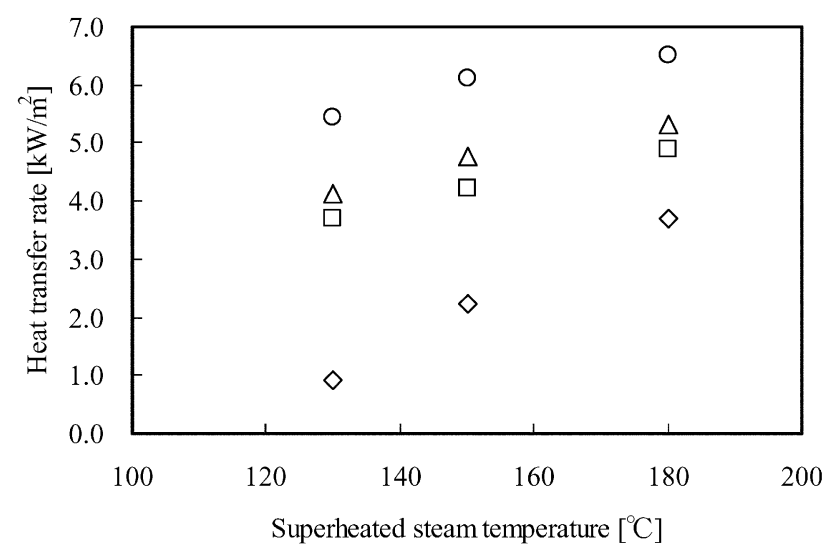

Fig. 6. The effect of the far infrared heating on the heat transfer rate in the superheated steam treatment.

$\diamond$ superheated steam ; $\square$ superheated steam + ceramic heater $230^{\circ} \mathrm{C} ; \triangle$ superheated steam + ceramic heater $250^{\circ} \mathrm{C}$; $\bigcirc$ superheated steam + ceramic heater $300^{\circ} \mathrm{C}$.

Table 1. Estimated effective temperature of the SHS stagnated under the ceramic heater for radiative heat transfer.

\begin{tabular}{ccccccc}
\hline & \multicolumn{6}{c}{ Superheated steam temperature $\left[{ }^{\circ} \mathrm{C}\right]$} \\
\hline Surface temperature of & \multicolumn{2}{c}{130} & \multicolumn{2}{c}{150} & \multicolumn{2}{c}{180} \\
\cline { 2 - 7 } ceramic heater $\left[{ }^{\circ} \mathrm{C}\right]$ & $0.5 \mathrm{~m} / \mathrm{s}$ & $1.0 \mathrm{~m} / \mathrm{s}$ & $0.5 \mathrm{~m} / \mathrm{s}$ & $1.0 \mathrm{~m} / \mathrm{s}$ & $0.5 \mathrm{~m} / \mathrm{s}$ & $1.0 \mathrm{~m} / \mathrm{s}$ \\
& $*$ & $*$ & $*$ & $*$ & $*$ & $*$ \\
\hline 230 & 180 & 230 & 190 & 220 & 210 & 220 \\
250 & 220 & 250 & 220 & 250 & 250 & 250 \\
300 & 250 & 300 & 240 & 300 & - & 260 \\
\hline
\end{tabular}

* Flow rate of the superheated steam

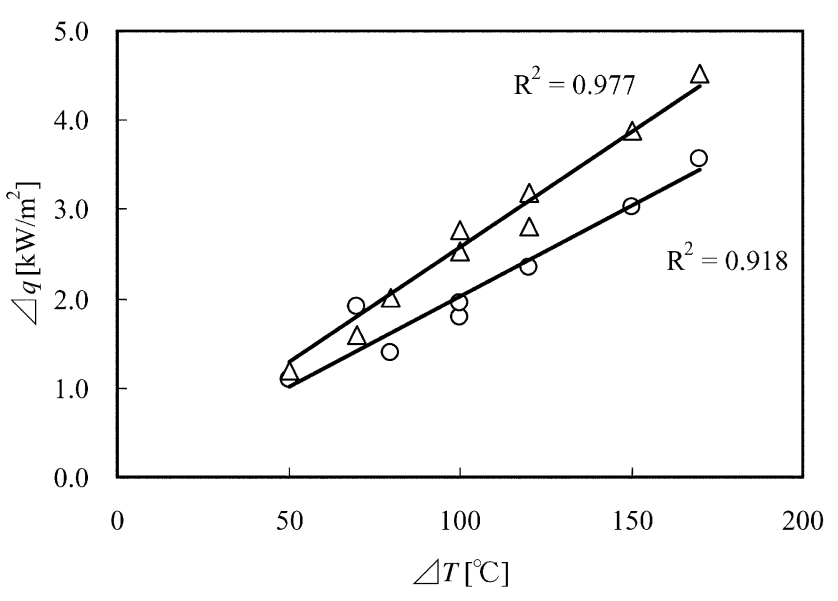

Fig. 7. The relationship between $\Delta T$ (temperature difference between ceramic heater and superheated steam) and $\Delta q$ (increase in heat transfer rate by combining far infrared heating with superheated steam).

Oflow rate of the SHS was $0.5 \mathrm{~m} / \mathrm{s}, \triangle$ flow rate of the SHS was $1.0 \mathrm{~m} / \mathrm{s}$. ceramic heater and the heat transfer rate The effect of FIH on the heat transfer rate of the superheated steam treatment was remarkable, as shown in Figure 6. But the effect on the heat transfer rate decreased when the temperature difference between the superheated steam and the ceramic heater became small. The reason is that, in this study, the temperature of the wall of the test chamber was brought to the same level as the SHS temperature. Therefore, the temperature difference between the ceramic heater and the SHS or the wall of the test chamber, $\left(T_{\mathrm{h}}\right.$ $-T_{\mathrm{w}}$ ), became small, and the effect of the radiative heating from the ceramic heater decreased, as predicted by Equation (7).

Advantages of combining infrared heating with superheated steam The increase in the heat transfer rate as a result of combining $\mathrm{FIH}$ with SHS, $\Delta q$, was plotted against the difference between the temperature of the ceramic heater and that of the SHS or the wall of the test chamber, $\Delta T=\left(T_{\mathrm{h}}-T_{\mathrm{s}}\right)$, as shown in Figure 7 . The results show that $\Delta q$ increased linearly with $\Delta T$. This indicates that it is easy to increase the heat transfer rate by increasing the temperature of the ceramic heater, because the temperature response of the ceramic heater is much faster with a smaller energy input than the temper- 
ature response of the SHS. Furthermore, the temperature of the ceramic heater can also be controlled much more easily than the temperature of the SHS. It is also obvious that a high heat transfer rate could be obtained easily even at a low flow rate of superheated steam by combining SHS with FIH, as shown in Figure 7.

The results of this study showed that the proposed new SHS process, in which SHS and FIH are combined, has remarkable potential applications in thermal food processing. The energy advantages need to be further analyzed.

\section{References}

Chow, L.C. and Chung, J.N. (1983). Evaporation of water into a laminar stream of air and superheated steam. Int. J. Heat Mass Transfer, 26 (3), 373-380.

Fraile, P. and Burg, P. (1997). Influence of convection heat transfer on the reheating of a chilled ready-cooked dish in an experimental superheated seam cell. J. Food Eng., 33, 263-280.

Iyota, H., Nishimura, N., Onuma, T. and Nomura, T. (2001). Drying of sliced raw potatoes in superheated steam and hot air. Drying technology, 19 (7), 1411-1424.

Li, Y.B., Yagoobi, J.S. and Yamsaengsung, R. (1993). Superheated steam impingement drying of tortilla chips. Drying technology, 17 (1 and 2), 191-213.

McAdams, W.H. (1933). “Heat Transmission.” McGRAW-HILL Book Company Inc., New York, p. 180.
Nishimura, N., Nomura, T. and Ueda, S. (1989). Heat and mass transfer with water evaporation into superheated steam. Mem. Fac. Eng. Osaka City Univ., 30, 1-10.

Nishioka, F., Asaoka, D. and Yamazaki M. (2004). The research on the high quality of the boiled-dried adductor muscle of scallop (Shiraboshi) using the superheated steam. Nippon Shokuhin Kagaku Kogaku Kaishi, 51 (3), 167-171 (in Japanese).

Perry, J.H. (1963). "Chemical Engineer's Handbook (4th ed,)." Kogakusha Co., Ltd., Tokyo, p. 3-95.

Rohsenow, W.M. and Choi, H.Y. (1961). "Heat, Mass, and Momentum Transfer.” Prentice-Hall Inc., New Jersey, p. 148, p. 346.

Shibata, H., Mada, J. and Shinohara, H. (1988). Drying mechanism of sintered spheres of glass beads in superheated steam. Ind. Eng. Chem. Res., 27, 2353-2362.

Taechapairoj, C., Dhuchakallaya, I., Soponronnarit, S. Wetchacama, S. and Prachayawarakorn, S. (2003). Superheated steam fluidized bed paddy drying. J. Food Eng., 58, 67-73.

Tanishita, I. (1986). "Dennetsu Kogaku." Shokabo company, Ltd., Tokyo, p. 216, p. 242. (in Japanese)

The society of chemical engineers (1988). "Chemical Engineer's Handbook (5th ed.).” Maruzen C., Ltd., Tokyo, p. 1364. (in Japanese)

Wu, C.H., Dacis, D.C. and Choung, J.N. (1989). Simulated dehydration of wedge-shaped speciments in turbulent flow of superheated steam and air. Drying technology, 7 (4), 761-782.

Yoshida, T. and Hyodo, T. (1970). Evaporation of water in air, humid air, and superheated steam. Ind. Eng. Chem. Process Des. Develop., 9 (2), 207-214. 